Bull. Chem. Soc. Ethiop. 2021, 35(1), 151-160.

(C) 2021 Chemical Society of Ethiopia and The Authors

ISSN 1011-3924

DOI: https://dx.doi.org/10.4314/bcse.v35i1.13

Printed in Ethiopia

Online ISSN 1726-801X

\title{
INVESTIGATIONS ON STRUCTURAL, OPTICAL, AND IMPEDANCE SPECTROSCOPY STUDIES OF TITANIUM DIOXIDE NANOPARTICLES
}

\author{
S.C. Vella Durai ${ }^{1 *}$, E. Kumar ${ }^{2}$ and D. Muthuraj ${ }^{3}$ \\ ${ }^{1}$ Department of Physics, JP College of Arts and Science, Agarakattu, Tenkasi, Tamilnadu, India \\ ${ }^{2}$ School of Science, Department of Physics, Tamil Nadu Open University, Chennai. Tamilnadu, \\ India \\ ${ }^{3}$ PG and Research Department of Physics, The M.D.T. Hindu College, Tirunelveli, Tamilnadu, \\ India
}

(Received February 4, 2020; Revised April 2, 2021; Accepted April 4, 2021)

\begin{abstract}
This article explains a novel synthesis for producing titanium dioxide $\left(\mathrm{TiO}_{2}\right)$ nanoparticles by a sol-gel technique using titanium tetraisopropoxide as a titanium source. The synthesized nanoparticles were analyzed using many measurements like X-ray diffraction (XRD), HRTEM, absorption UV spectroscopy, FTIR, and ac impedance spectroscopy. X-ray peaks were used to calculate the crystallite size and lattice strain by Williamson-Hall method. Crystallite size calculated from x-ray diffraction using the Scherrer equation gives an approximate size and cannot be used for measurements. $\mathrm{TiO}_{2}$ nanoparticles are found to possess a tetragonal structure with a crystalline size around $12 \mathrm{~nm}$. Particle size was confirmed by HRTEM images. The optical studies response for the nanoparticles showed the possible visible absorption peaks for $\mathrm{TiO}_{2}$ nanoparticles are $323 \mathrm{~nm}$. Bandgap energy $\left(\mathrm{E}_{\mathrm{g}}\right)$ of the $\mathrm{TiO}_{2}$ nanoparticle calculated from UV visible absorption spectra is discussed, and the bandgap is $3.14 \mathrm{eV}$. FTIR spectra showed vibration bands of the Ti-O network. AC Conductivity properties of $\mathrm{TiO}_{2}$ nanoparticles are studied in the frequency range 1 to $8 \mathrm{MHz}$ at varying temperatures. The conductivity of the $\mathrm{TiO}_{2}$ nanoparticle is found to be constant in the low angular frequency region. Dielectric parameters were analyzed at different temperatures and frequencies.
\end{abstract}

KEY WORDS: Conductivity, Dielectric, Nanoparticles, Titanium dioxide, Structural studies

\section{INTRODUCTION}

Today researchers and scientists are very interested in preparing and using very clean, developed energy and living. For the above-mentioned purpose, it is necessary to synthesize metal oxide with new and good properties [1]. Nanomaterials have different structures and shapes, varied with optical and electrical studies. The size of the nanoparticle decreases as the specific surface area increases. Shape control has a very important role in the nanoscience field. Many excellent research articles on the synthesis of metal oxide nanoparticles have been published in recent years [2]. To inorganic nanoparticles with a good surface action from agglomeration, many researchers have worked various techniques to improve nanoparticles; thin films and surface action related have been focused. Among the metal oxide nanoparticles, titanium dioxide $\left(\mathrm{TiO}_{2}\right)$ has a very important metal oxide for application in ceramic materials, gas sensors, photocatalysis, coating, and solar cell, it has been attracting the development of practical applications. $\mathrm{TiO}_{2}$ metal oxide has two different crystal structures like tetragonal (rutile and anatase) and orthorhombic (brookite) and each has its own high potential applications [3]. $\mathrm{TiO}_{2}$ is a good functional material due to its having good properties such as superconductivity, low cost, high refractive index, and corrosion resistance. Nowadays, $\mathrm{TiO}_{2}$ is used as a white pigment in cosmetic and paint applications, photonic crystals, coating for bone implants, and components in electroceramics [4]. Many research articles explaining $\mathrm{TiO}_{2}$ have different shapes like nanopowder [5], nanoparticles [6], nanorods [7], nanotubes, and nanowires [8]. $\mathrm{TiO}_{2}$ has

*Corresponding author. E-mail: duraipree@gmail.com

This work is licensed under the Creative Commons Attribution 4.0 International License 
nice photo catalytic behavior and is mostly used as catalysts for the decay of a difference of organic and inorganic pollutants. In most cases, nanoparticles are prepared through liquid phase reaction, acid phase reaction, and gas-phase reaction. Most of the methods have been established for $\mathrm{TiO}_{2}$ nanoparticle syntheses such as hydrothermal method [9], sol-gel technique [10], chemical vapor deposition [11], direct oxidation, and others. Among them, the sol-gel method is one of the best most controlled methods due to its possibility of deriving a unique tetragonal structure at low reaction room temperatures and excellent chemical route [12]. Sol-gel is not only a rapid method and also cleaner, faster and economical compared to other conventional methods, and this method is chosen for producing high purity $\mathrm{TiO}_{2}$ nanoparticles for the present work. $\mathrm{TiO}_{2}$ nanoparticles were characterized by powder X-ray diffraction method, highresolution transmission electron microscope, UV-Vis spectra, FTIR, conductivity, and dielectric studies.

\section{EXPERIMENTAL}

\section{Materials}

Titanium tetraisopropoxide (TTIP, 99.9\%, Merck Chemicals, India) and acetic acid $\left(\mathrm{CH}_{3} \mathrm{COOH}, 99 \%\right.$, Merck Chemicals, India) were used to prepare the titanium dioxide nanoparticles. Deionized water was used in this study.

Synthesis of titanium dioxide nanoparticles

In this synthesis process [13], the two different solutions $5.8 \mathrm{~mL}$ of titanium tetraisopropoxide (TTIP) was mixed with $20 \mathrm{~mL}$ deionized water and $25 \mathrm{~mL}$ deionized mixed with $2.5 \mathrm{~mL}$ of acetic acid. The acetic acid solution is mixed within drop-wise TTIP solution during stirring, stirred in continuously for 3 hours to obtain a clear white colour solution. After one hour, the solution was kept in a micro oven at $40{ }^{\circ} \mathrm{C}$ for $10 \mathrm{~min}$ to obtain a colloidal solution. The obtained solution was dried at $60{ }^{\circ} \mathrm{C}$ to get white colour $\mathrm{TiO}_{2}$ nanoparticles. Prepared nanoparticles were crushed into fine powders with a mortar. As-prepared samples were characterized.

\section{Equipments}

The powder XRD method of the titanium dioxide nanoparticle was analyzed using powder XRD (PANalytical X-Pert Pro) using CuK $\alpha 1, \lambda=0.15 \mathrm{~nm}$ radiations at $30 \mathrm{~mA}, 40 \mathrm{kV}$ with $\mathrm{Cu} \mathrm{K} \alpha$ radiation $(\lambda=1.54060 \AA)$, with an angle between $10-80^{\circ}$. The particle size of the $\mathrm{TiO}_{2}$ nanoparticle was carried out from HRTEM (JOEL JEM 2000). The FT-IR spectra of the $\mathrm{TiO}_{2}$ were recorded using Fourier transform infra-red spectroscopy (JASCO FTIR-4100), a range of wavelengths as 400 to $4000 \mathrm{~cm}^{-1}$. The optical spectra of the $\mathrm{TiO}_{2}$ were recorded using UV Visible spectroscopy (UV-2600) in the wavelength range $200-1200 \mathrm{~cm}^{-1}$. AC impedance spectroscopic studies were analyzed (computer-controlled Zahnner zennium IM6 meter) within the frequency range of 1 to $8 \mathrm{MHz}$ at different temperatures.

\section{RESULTS AND DISCUSSION}

\section{Powder X-ray diffraction analysis}

Figure 1 shows the XRD patterns of the $\mathrm{TiO}_{2}$ nanoparticles prepared by chemical sol-gel methods. The powder XRD study indicates that the nanomaterial was synthesized from pure $\mathrm{TiO}_{2}$ phase and crystalline structure. The line broadening of the diffraction peak indicates that 
the prepared materials in the nanoscale range. The XRD technique was carried out over the diffraction angle in between $2 \theta\left(10-80^{\circ}\right)$. The peaks of Figure 1 can be indexed as a tetragonal phase of $\mathrm{TiO}_{2}$ nanoparticles with a lattice constant of $\mathrm{a}=3.7852 \AA$ and $\mathrm{c}=9.5139 \AA$, in good agreement with JCPDS card no. 21-1272 [14]. In prepared $\mathrm{TiO}_{2}$ nanoparticles, the peak at $25.5^{\circ}$ corresponding to the plane (101). The peak position at 37.6, 47.1, 53.5, 62.4, 68.5 and $75.0^{\circ}$ are in accordance to plane of (004), (200), (105), (213), (116) and (215) with the $\mathrm{TiO}_{2}$ anatase phase [15]. Some other phases could not be detected in the pattern. The Scherrer formula is used to calculate the crystalline size of the nanoparticles:

$\mathrm{d}=\frac{0.94 \lambda}{\beta \cos \theta}$

where $\mathrm{d}$ is the diameter of the crystalline particle, $\lambda$ is the wavelength of $\mathrm{X}$-ray radiation, $\mathrm{B}$ is the full width at half-maximum (FWHM) of the peak and $\theta$ is the angle of diffraction. The crystalline size of the nanoparticle obtained is $12 \mathrm{~nm}$, which is coincident with the HRTEM investigation shown in Figure 3.

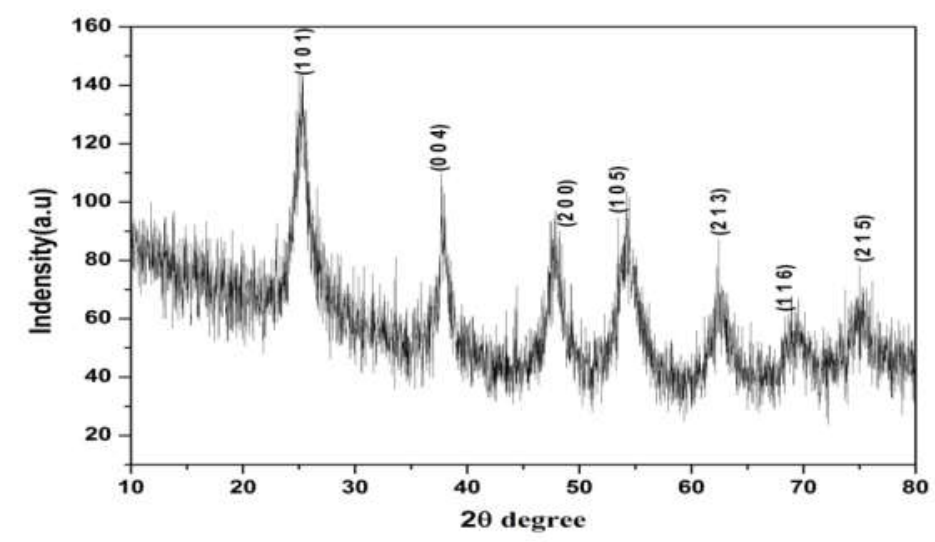

Figure 1. XRD pattern for $\mathrm{TiO}_{2}$ nanoparticles.

\section{Williamson - Hall analysis}

The X-ray peak evidence crystalline size along with the large strain related to the nanoparticles. From the XRD data, the broadening $\left(\beta_{\mathrm{T}}\right)$ of the peaks is due to the relation of crystalline size $\left(\beta_{\mathrm{d}}\right)$ and lattice microstrain $\left(\beta_{\varepsilon}\right)$. The $\beta_{\mathrm{T}}$ was corrected, corresponding to all x-ray diffraction peaks of $\mathrm{TiO}_{2}$ nanomaterials used by the relation is

$\beta_{T}=\beta_{D}+\beta_{Z}$

The crystalline sizes were found using the Scherrer equation is

$\mathrm{d}=\frac{0.94 \lambda}{\beta \cos \theta}$

The average crystallite size is around $12 \mathrm{~nm}$. The microstrain devolved in nanoparticles due to crystal defect and distortion was found using the equation:

$\varepsilon=\frac{\beta_{\mathrm{T}}}{4 \tan \theta}$

From the above equations, it was confirmed that the X-ray diffraction peaks width from

Bull. Chem. Soc. Ethiop. 2021, 35(1) 
crystalline size changes as $1 / \cos \theta$ strain changes as $\tan \theta$. Therefore, simply sum of the above equations are

$\varepsilon_{T}=4 \varepsilon \tan \theta+\frac{k \lambda}{d \cos \theta}$

By rearranging the above equation is [16]

$\beta_{\mathrm{T}} \cos \theta=4 \varepsilon \sin \theta+\frac{k \lambda}{d}$

The above equations are called the $\mathrm{W}-\mathrm{H}$ equation. The plot is drawn with $\beta_{\mathrm{T}} \cos \theta$ along the $\mathrm{y}-$ axis and $4 \sin \theta$ along the $\mathrm{x}$-axis (Figure 2). The linear fit was drawn and the strain was calculated using the slope of the fit and crystallite size was found by the y-intercept. The crystalline size of $\mathrm{TiO}_{2}$ nanoparticles is around $12 \mathrm{~nm}$ and micros strain is -0.009 .

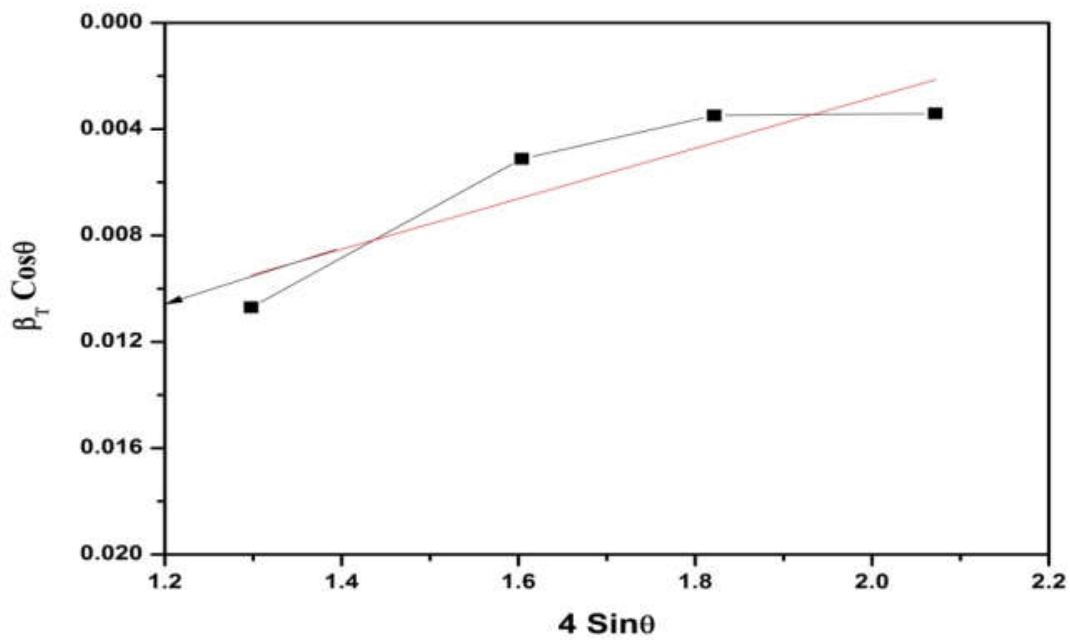

Figure 2. W-H Plot for $\mathrm{TiO}_{2}$ nanoparticles.

High-resolution transmission electron microscope (HRTEM)

High-resolution transmission electron microscope (HRTEM) was used and further explains the crystallite nature, particle size, and morphology. The HRTEM image (Figure. 3) shows that the crystalline, spherical shape and morphology of prepared $\mathrm{TiO}_{2}$ nanoparticles were strongly confirmed [17]. HRTEM images (Figure 3 (a), (c) and (d)) indicate that the $\mathrm{TiO}_{2}$ nanoparticle was small, at about around $12 \mathrm{~nm}$. Figure 3 (b) and (c) images are almost in accordance with Figure 3(a). From the figure, The $\mathrm{TiO}_{2}$ nanoparticles have confirmed the shape of spherical. HRTEM images (Figure 3 (b)), indicates the SAED (selected area electron diffraction) pattern of $\mathrm{TiO}_{2}$ nanoparticles. The HRTEM image in accordance with the powder XRD result. 
Structural, optical, and impedance spectroscopy studies of titanium dioxide nanoparticles 155

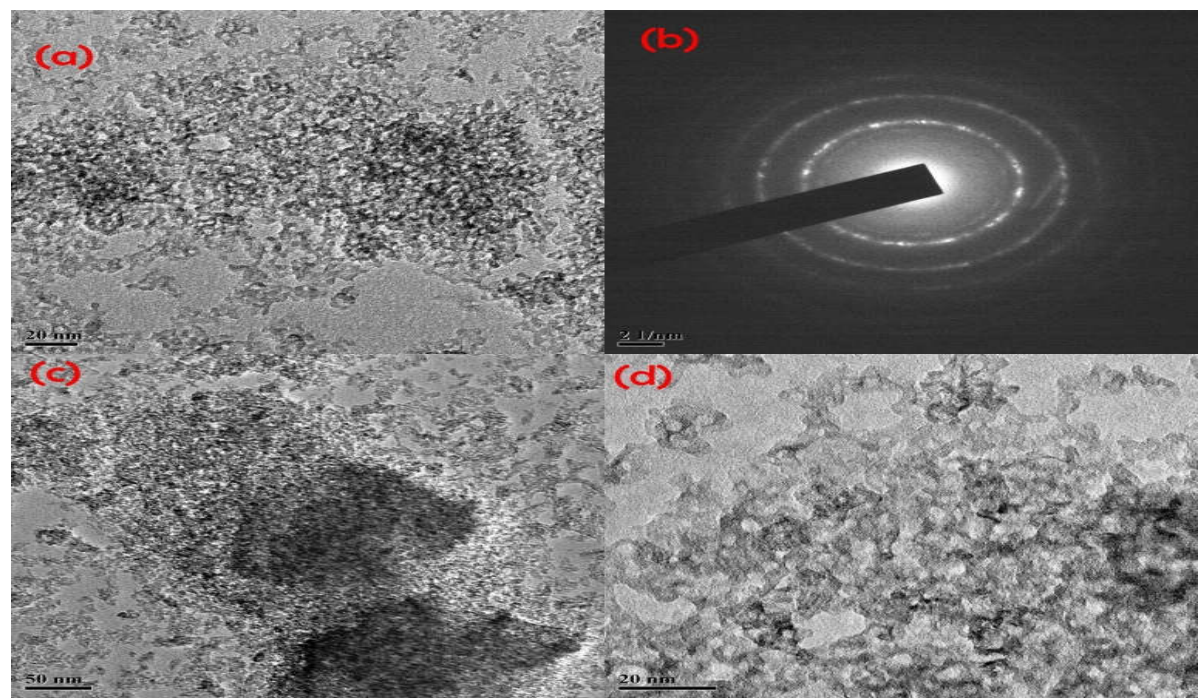

Figure 3. (a), (c) and (d) HRTEM image of $\mathrm{TiO}_{2}$ nanoparticles and (b) SAED pattern of $\mathrm{TiO}_{2}$ nanoparticles.

Fourier transform infra-red spectroscopy (FTIR) analysis

FTIR spectra were used to analyze the various functional groups in $\mathrm{TiO}_{2}$ nanoparticles. Figure 4 shows the FT-IR spectra of sol-gel prepared $\mathrm{TiO}_{2}$ in the range of $500-4000 \mathrm{~cm}^{-1}$. The peak observed at $3208.0046 \mathrm{~cm}^{-1}$ is due to the stretching vibration of the O-H group [18]. The peak obtained at $1618.948 \mathrm{~cm}^{-1}$ was attributed to the Ti-OH bending mode of water [19].

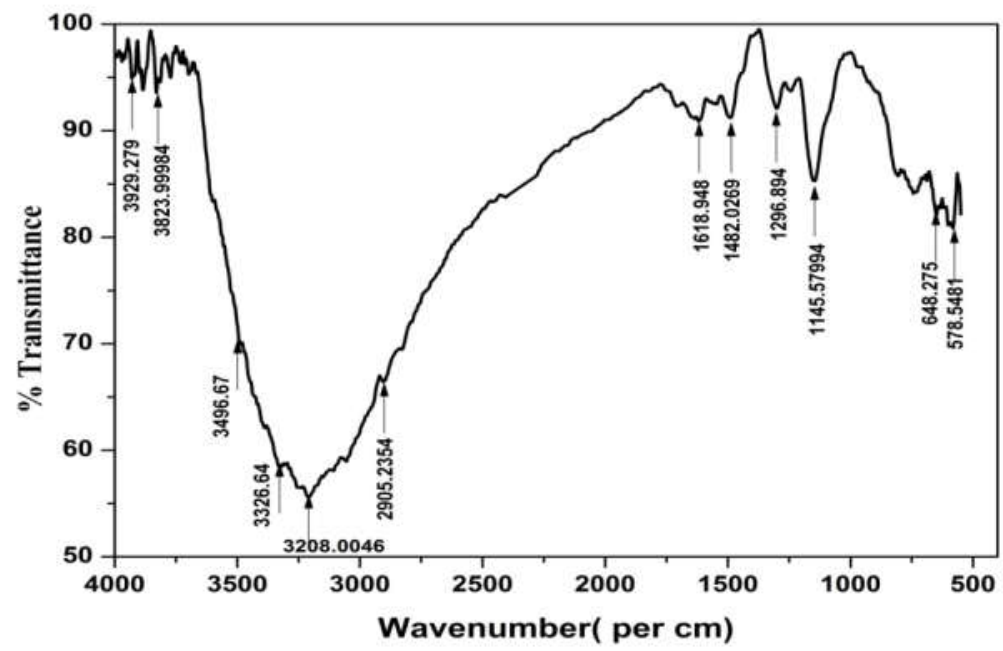

Figure 4. FTIR pattern of $\mathrm{TiO}_{2}$ nanoparticles.

Bull. Chem. Soc. Ethiop. 2021, 35(1) 
In the spectra of pure $\mathrm{TiO}_{2}$, the peak observed at $578.5481 \mathrm{~cm}^{-1}$ is due to the stretching vibration of Ti-O, and $1482.0269 \mathrm{~cm}^{-1}$ shows stretching vibrations of Ti-O-Ti [20]. Only the more strong peaks lie between 500 to $4000 \mathrm{~cm}^{-1}$, and which have been attributed to formed $\mathrm{TiO}_{2}$ nanoparticles. It measured various well-defined peaks are 648.275, 1145.57994, 1296.894, $1618.948,3326.64$, and $3496.67 \mathrm{~cm}^{-1}$. The $\mathrm{TiO}_{2}$ nanoparticle prepared by this method is of good quality and can be used for further applications.

\section{UV-Visible spectroscopy analysis}

The optical studies of the prepared nanoparticles were analyzed using UV-Visible spectra. Figure 5 shows the absorbance of the prepared nanomaterials in the nanoscale range at room temperature. The UV spectra between 200-1250 nm were analyzed. It shows a peak at $323 \mathrm{~nm}$ with absorbance, which means that it explains good absorbance in the UV region.

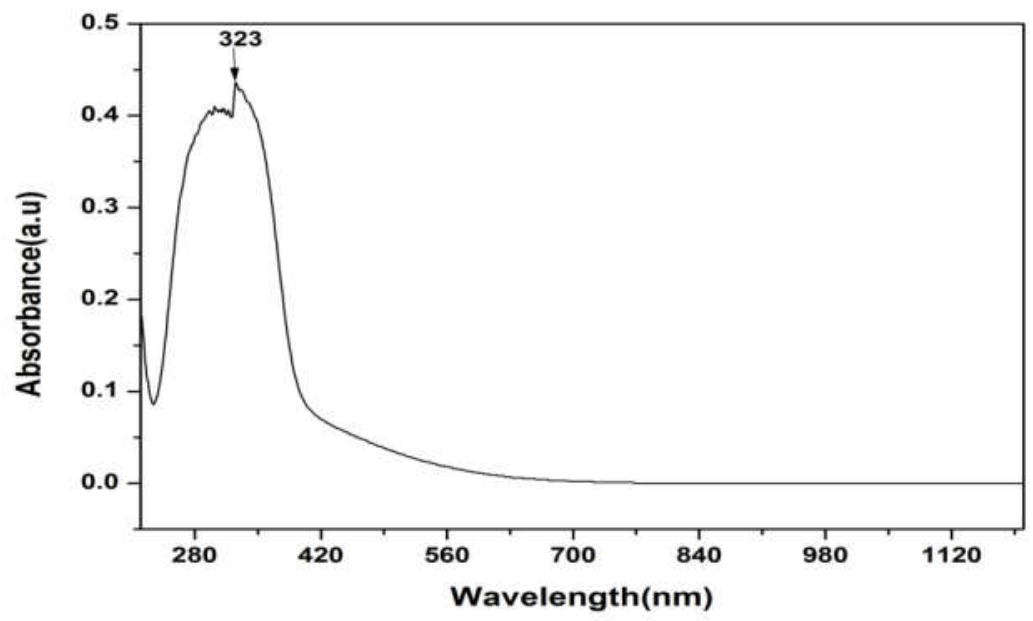

Figure 5. UV pattern of $\mathrm{TiO}_{2}$ nanoparticles.

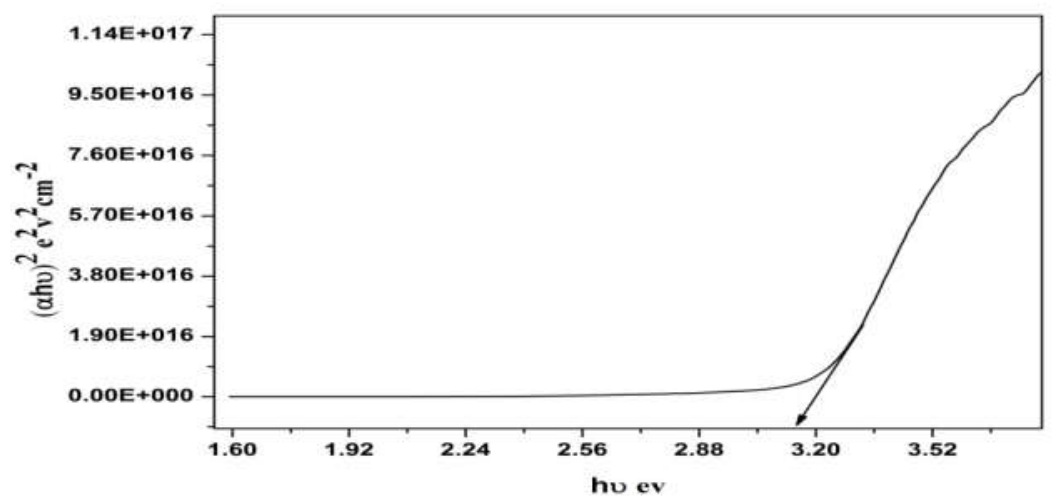

Figure 6. Band gap of $\mathrm{TiO}_{2}$ nanoparticles. 
To find the value of energy bandgap $\left(\mathrm{E}_{\mathrm{g}}\right)$, it is measured from the fundamental absorption. The relation in between the $\alpha$ and $h \gamma$ can be written as:

$\alpha E=A\left(E-E_{g}\right)$

( $\mathrm{E}=\mathrm{h} \gamma, \gamma=\mathrm{c} / \lambda$ ) where $\mathrm{A}$ is a constant, $\mathrm{E}$ is incident photon energy, $\alpha$ is an absorption coefficient and $\mathrm{E}_{\mathrm{g}}$ is bandgap energy of the materials. Bandgap energy can be found accurately from the plots of $h v$ against $(\alpha h v)^{2}$. The straight-line portion of the plot (hv vs $(\alpha h v)^{2}$ to $\alpha=0$ ) may be obtained by bandgap energy [21]. $\mathrm{E}_{\mathrm{g}}$ value of $\mathrm{TiO}_{2}$ nanoparticles is $3.14 \mathrm{eV}$ as calculated using Figure 6. The $\mathrm{TiO}_{2}$ nanoparticles have large bandgap energy and can be used for further more applications like photocatalytic [22].

\section{AC conductivity analysis}

As prepared $\mathrm{TiO}_{2}$ nanoparticles were analyzed in terms of AC conductivity. In order to raise the activity of electron movement in nanostructures, the AC conductivity studying is a very important role to find whether the nanoparticle has high conductivity or not. From the band theory, the conductivity is more means that the electrons are more in the conduction band [23]. Figure 7 shows that the frequency-dependent conductivity of $\mathrm{TiO}_{2}$ nanoparticles of different temperatures in the angular frequency range of 0.5 to $6.5 \mathrm{rad} / \mathrm{s}$. The conductivity $\left(\sigma_{\mathrm{ac}}\right)$ was obtained by the relation of

$\sigma_{a c}=\varepsilon_{0} \varepsilon_{r} \tan \theta$

$\omega(\omega=2 \pi \mathrm{f})$ is an angular frequency and $\varepsilon_{\mathrm{r}}$ is the relative permittivity. Generally, conductivity can be written as

$\sigma(\omega)=B(T) \omega^{s(T)}$

Here, the first term is dependent on temperature, and the power of angular frequency will give information about hopping mechanism correlation [24]. The conductivity of $\mathrm{TiO}_{2}$ nanoparticles was calculated in the temperature between $303 \mathrm{~K}$ to $383 \mathrm{~K}$. At low frequencies, conductivity has constant at all temperatures, and it has been changed at the high temperatures range. This conductivity variation has occurred in the prepared samples due to the polarization effect. The conductivity of $\mathrm{TiO}_{2}$ nanoparticles is $989 \mathrm{~S} / \mathrm{cm}$ at $383 \mathrm{~K}$ in the angular frequency of $6.5 \mathrm{rad} / \mathrm{s}$ and $323 \mathrm{~S} / \mathrm{cm}$ at $303 \mathrm{~K}$. The highest temperature $383 \mathrm{~K}$ has shown a high conductivity as compared to the other temperature.

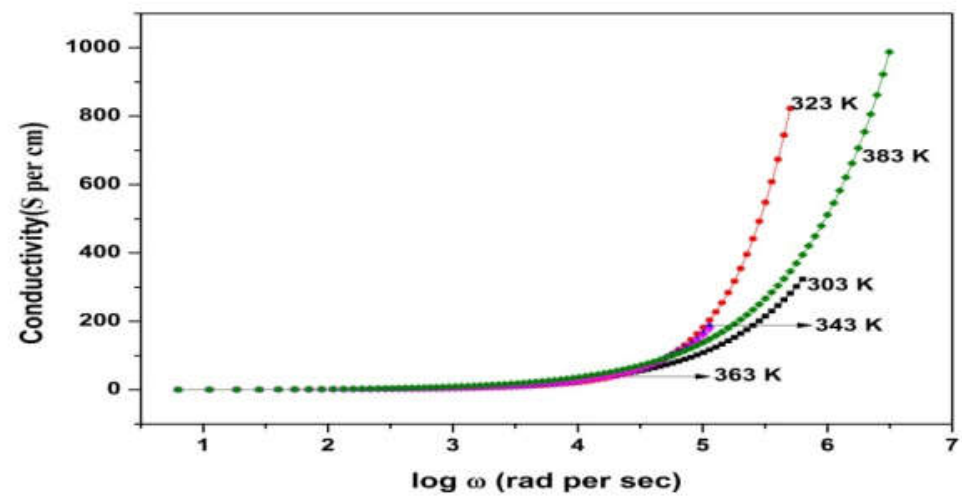

Figure 7. Conductivity image of $\mathrm{TiO}_{2}$ nanoparticles.

Bull. Chem. Soc. Ethiop. 2021, 35(1) 
Dielectric analysis

The frequency-dependent analysis is carried out to study the electrical homogeneity of the nanomaterial confirming the relaxation mechanism as well as the behaviour of electrical conduction [25]. This analysis helps to carry out the dielectric constant of the nanomaterial. The microelectronics field industry needs very few dielectric constant materials. The dielectric constant was observed in the present study, it is shown in Figure 8. The obtained dielectric constant for the prepared $\mathrm{TiO}_{2}$ is very less when compared to the bulk materials. The dielectric constant value obtained is very less when it has low angular frequency compared to all different temperatures. At high angular frequencies, the dielectric constant has a constant at all temperatures, and it has been varied at the low angular frequency range.

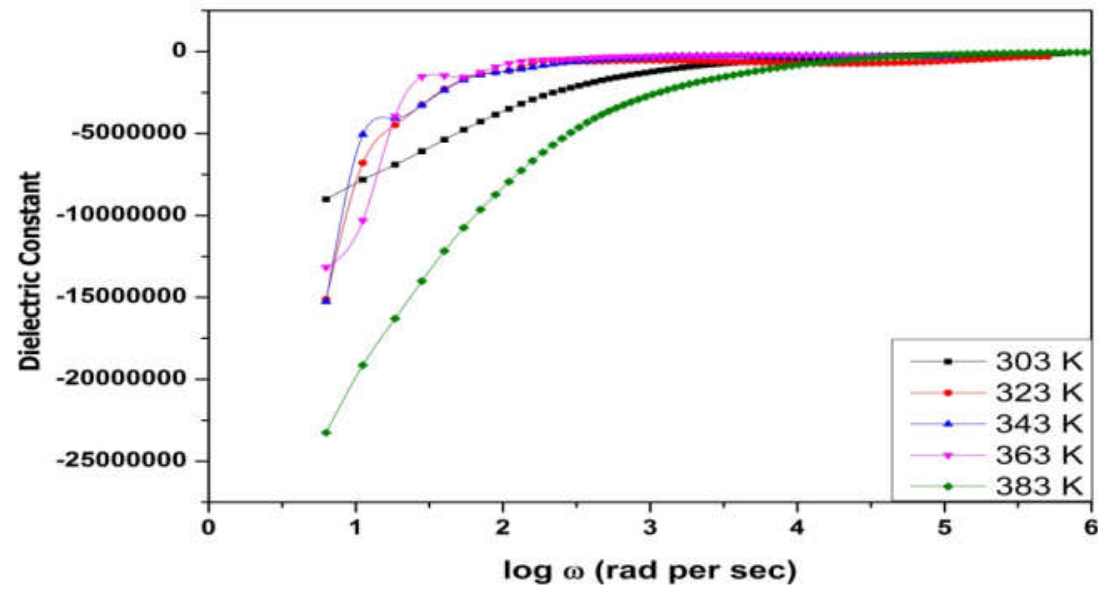

Figure 8. Logarithm of omeha versus dielectric constant ( $\left.\boldsymbol{\varepsilon}^{\prime}\right)$ of $\mathrm{TiO}_{2}$ nanoparticles.

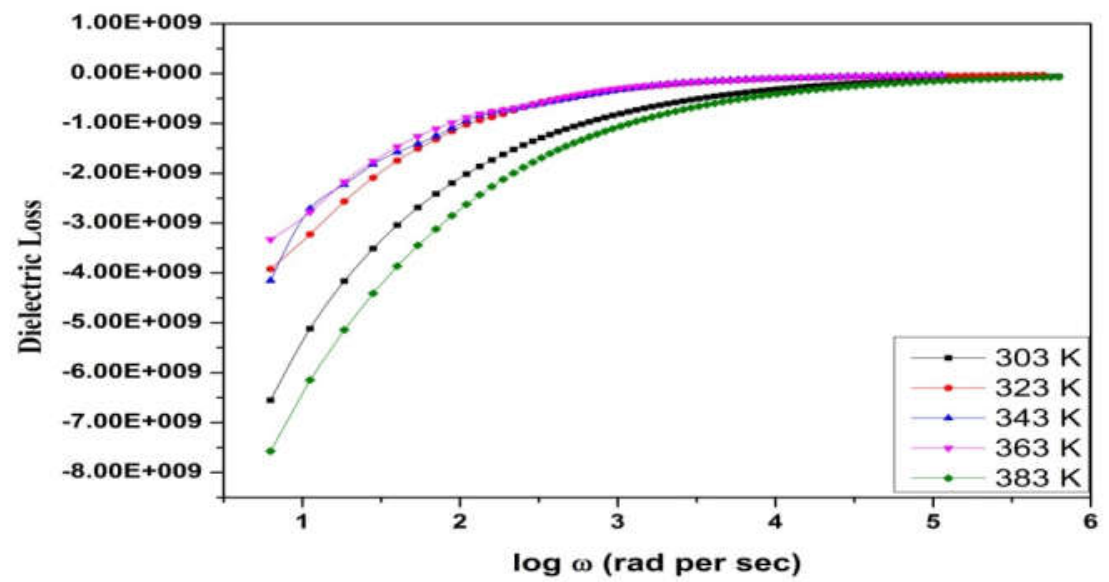

Figure 9. Logarithm of omeha versus dielectric loss $(\varepsilon ")$ of $\mathrm{TiO}_{2}$ nanoparticles. 
The $\varepsilon$ ' is high at a low angular frequency area for all temperatures. It is the reason due to the space charge region at the electrode interface, which is non-Debye nature, where the space charge area with respect to angular frequency is expelled in terms of ion diffusion. At high frequencies due to the high reversal of the field at the electrode interface, the distribution of charge carriers, ions, towards the $\varepsilon$ ' decreases with an increase in temperature [26]. The dielectric loss was observed as the energy dissipated and generally consists of the distribution ion as well as from the polarization of a charge. The log $\omega$ vs $\varepsilon^{\prime \prime}$ plots for $\mathrm{TiO}_{2}$ nanoparticles with different temperatures is given in Figure 9. The dielectric loss becomes very high at higher angular frequencies due to free charge motion. At low angular frequencies, the dielectric loss has varied at all temperatures, and it has been constant at the high angular frequency range. The variation in the slope is distributed to space charge effects at low frequencies. The highest temperature $383 \mathrm{~K}$ has shown a good result as compared to the other temperature.

\section{CONCLUSION}

The metal oxide $\mathrm{TiO}_{2}$ nanoparticles have been prepared by sol-gel technique and characterized by XRD, HRTEM, FTIR, UV, and AC impedance techniques. The XRD study reveals the crystalline nature of the prepared nanoparticles. The microstrain was calculated by the W-H plot method and is -0.09 . The particle size was calculated from the HRTEM image. The FTIR study confirms the functional group of nanoparticles. The energy band gap was calculated by the UV absorption method and is $3.14 \mathrm{eV}$. The temperature dependence of the conductivity of nanoparticles was analyzed with the different temperature ranges. The highest conductivity has been measured at $989 \mathrm{~S} / \mathrm{cm}$ for $383 \mathrm{~K}$ in the angular frequency of $6.5 \mathrm{rad} / \mathrm{s}$. The dielectric parameter increased with the increase in all temperatures.

\section{ACKNOWLEDGEMENT}

The authors are thankful to the authorities of JP College of Arts and Science, Agarakattu, Tenkasi for providing necessary research facilities.

\section{REFERENCES}

1. Khan, I.; Saeed, K.; Khan, I. Nanoparticles: Properties, applications and toxicities. Arabian J. Chem. 2019, 12, 908-931.

2. Lane, M.K.M.; Zimmerman, J.B. Controlling metal oxide nanoparticle size and shape with supercritical fluid synthesis. Green Chem. 2019, 21, 3769-3781.

3. Verma, R.; Gangwar, J.; Srivastava, A.K. Multiphase $\mathrm{TiO}_{2}$ nanostructures: A review of efficient synthesis, growth mechanism, probing capabilities, and applications in bio-safety and health. RSC Adv. 2017, 7, 44199-44224.

4. Lai, Y.; Cheng, Y.; Yang, H.; Yang, Y.; Huang, J.; Chen, Z.; Wang, X.; Lin, C. Progress in $\mathrm{TiO}_{2}$ nanotube coatings for biomedical applications: A review. J. Mater. Chem. B, 2018, 6, $1862-1886$

5. El sherbiny, S.; Morsy, F.; Samir, M.; Fouad, O. Synthesis, characterization and application of $\mathrm{TiO}_{2}$ nanopowders as special paper coating pigment. Appl. Nanosci. 2013, 4, 305-313.

6. Shi, H.; Magaye, R.; Castranova, V.; Zhao, J. Titanium dioxide nanoparticles: A review of current toxicological data. Part. Fibre Toxicol. 2013, 10, 15.

7. Wu, B.; Liu, D.; Mubeen, S.; Chuong, T.T.; Moskovits, M.; Stucky, G.D. Anisotropic growth of $\mathrm{TiO}_{2}$ onto gold nanorods for plasmon-enhanced hydrogen production from water reduction. J. Am. Chem. Soc. 2016, 138, 1114-1117. 
8. Singh, D.; Ali, N. Synthesis of $\mathrm{TiO}_{2}$ and $\mathrm{CuO}$ nanotubes and nanowires. Sci. Adv. Mater. 2010, 2, 295-335.

9. Farooq, M.H.; Aslam, I.; Shuaib, A.; Anam, H.S.; Rizwan, M.; Kanwal, Q. Band gap engineering for improved photocatalytic performance of $\mathrm{CuS} / \mathrm{TiO}_{2}$ composites under solar light irradiation. Bull. Chem. Soc. Ethiop. 2019, 33, 561-571.

10. Vella Durai, S.C.; Ganapathi Raman, R.; Kumar, E.; Muthuraj, D. Structural, optical, morphological and thermal properties of $\mathrm{CuO}$ nanoparticles prepared by sol-gel technique. $J$. Nano-Electron. Phys. 2019, 11, 05011.

11. Battu, A.K.; Manandhar, S.; Ramana, C.V. Nanomechanical characterization of titanium incorporated gallium oxide nanocrystalline thin films. Mater. Today Nano 2018, 2, 7-14.

12. Macwan, D.P.; Dave, P.; Chaturvedi, S. A review on nano- $\mathrm{TiO}_{2}$ sol-gel type syntheses and its applications. J. Mater. Sci. 2011, 46, 3669-3686.

13. Kavitha, M.; Gopinathan, C.; Pandi, P. Synthesis and characterization of $\mathrm{TiO}_{2}$ nanopowders in hydrothermal and sol-gel method. Int. J. Adv. Res. Technol. 2013, 2, 102-108.

14. Barrocas, B.; Monteiro, O.C.; Nunes, M.R.; Slivestre, A.J. Influence of Re and Ru doping on the structural, optical and photocatalytic properties of nanocrystalline $\mathrm{TiO}_{2}$. SN Appl. Sci. 2019, 1, 556.

15. Samya, E.S.; Fatma, M.; Marwa, S.; Osama, O.S. Synthesis, characterization and application of $\mathrm{TiO}_{2}$ nanopowders as special paper coating pigment. Appl. Nanosci. 2014, 4, 305-313.

16. Mote, V.D.; Purushotham, Y.; Dole, B.N. Williamson-Hall analysis in estimation of lattice strain in nanometer-sized ZnO particles. J. Theor. Appl. Phys. 2012, 6, 1-8.

17. Daudre, C.F.; Baumann, J.S.; Migonney, V.; Spadavecchia, J. Highly crystalline sphere and rod-shaped $\mathrm{TiO}_{2}$ nanoparticles: A facile route to bio-polymer grafting. Front. Lab. Med. 2017, 1, 217-223.

18. Mugundan, S.; Rajamannan, B.; Viruthagiri, G.; Shanmugam, N.; Gobi, R.; Praveen, P.; Synthesis and characterization of undoped and cobalt-doped $\mathrm{TiO}_{2}$ nanoparticles via sol-gel technique. Appl. Nanosci. 2015, 5, 449-456.

19. Leon, A.; Reuquen, P.; Garín, C.; Segura, R.; Vargas, V.; Zapata, P.; Orihuela, P. FTIR and Raman characterization of $\mathrm{TiO}_{2}$ nanoparticles coated with polyethylene glycol as carrier for 2-methoxyestradiol. Appl. Sci. 2017, 7, 49.

20. Thangavelu, K.; Annamalai, R.; Arulnandhi, D. Preparation and characterization of nanosized $\mathrm{TiO}_{2}$ powder by sol-gel precipitation route. Int. J. Emerg. Technol. Adv. Eng. 2013, 3, 636-639.

21. Vella Durai, S.C.; Kumar, E.; Indira, R.; Muthuraj, D. Preparation and investigation on structural, optical and conductivity properties of polyaniline/titanium dioxide nanocomposites. J. Ovonic Res. 2020, 16, 345-353.

22. Hussain, M.; Ceccarelli, R.; Marchisio, D.L.; Fino, D.; Russo, N.; Geobaldo, F. Synthesis, characterization, and photocatalytic application of novel $\mathrm{TiO}_{2}$ nanoparticles. Chem. Eng. J. 2010, 157, 45-51.

23. Saravanan, P.; Ganapathy, M.; Charles, A.; Tamilselvan, S.; Jeyasekaran, R.; Vimalan, M. Electrical properties of green synthesized $\mathrm{TiO}_{2}$ nanoparticles, Adv. Appl. Sci. Res. 2016, 7, 158-168.

24. Vella Durai, S.C.; Kumar, E.; Muthuraj, D.; Bena Jothy, V. Investigations on structural, optical, and ac conductivity of polyaniline/manganese dioxide nanocomposites. Int. J. Nano Dimens. 2019, 10, 410-416.

25. Malathi, J.; Kumaravadivel, M.; Brahmanandhan, G.M.; Hema, M.; Baskaran, R.; Selvasekarapandian, S. Structural, thermal and electrical properties of PVA- $\mathrm{LiCF}_{3} \mathrm{SO}_{3}$ polymer electrolyte. J. Non-Cryst. Solids 2010, 356, 2277-2281.

26. Arunkumar, D.; Selvasekarapandian, S.; Nithya, H.; Sakunthala, A.; Hema, M. Dielectric, modulus and impedance analysis of $\mathrm{LaF}_{3}$ nanoparticles. Physica B 2010, 405, 3803-3807. 